\title{
MANAGING MASS CASUALTIES IN LIMITED RESOURCE SETTING: A COMPARISON BETWEEN A PERIPHERAL HOSPITAL AND FORWARD TREATMENT CENTER
}

\author{
Mobeen Ikram, Saira Mahboob*, Nudrat Zeba** \\ Combined Military Hospital Okara/National University of Medical Sciences (NUMS) Pakistan, *Bilawal Medical College, Jamshoro Pakistan, \\ ** Liaquat University of Medical and Health Sciences, Jamshoro Pakistan
}

\begin{abstract}
Objective: To share our experience of handling mass casualties at remote locations with an aim to help formulate a policy regarding future training of doctors.

Study Design: Case series.

Place and Duration of Study: Combined Military Hospital Thal Pakistan, from Jan 2016 to Sep 2018, including three months in Forward Treatment Center in operational areas.

Methodology: The injuries due to war trauma were included in our study. Resource management and changes made to accommodate the influx of mass trauma that required damage control surgery were described.

Results: A total of 16 casualties from two mass casualty incidents at two medical centers were included in our study. There was no difference in triage class $(p=0.96)$. Splinter injury limbs were most common injury. One patient required damage control surgery done at Combined Miliary Hospital with most requiring hemostasis prior to transport (8 at Combined Military Hospital versus 3 at Forward Treatment center), $p=0.346$.

Conclusion: Most of mass casualties at our hospital were minor injuries requiring immediate first aid. In addition, the damage control resuscitation and surgery done at these remote locations may have helped prevent mortality and morbidity in the more severely injured.
\end{abstract}

Keywords: Combined Military Hospital, Damage control surgery, Forward treatment center, Mass casualty.

How to Cite This Article: Ikram M, Mahboob S, Zeba Z. Managing Mass Casualties in Limited Resource Setting: A Comparison Between a Peripheral Hospital and Forward Treatment Center Pak Armed Forces Med J 2021; 71(6): 1989-1992. D Doi: https://doi.org/10.51253/pafmj.v6i6.2610

This is an Open Access article distributed under the terms of the Creative Commons Attribution License (https://creativecommons.org/licenses/by-nc/4.0/), which permits unrestricted use, distribution, and reproduction in any medium, provided the original work is properly cited.

\section{INTRODUCTION}

Pakistan has been actively fighting a war against terrorism for the last 18 years with many people losing their lives. Managing war related injuries including firearm injuries, bomb blast as well as improvised explosive device (IED) blast victims, is a challenging job for the doctors. Forward treatment centers are medical setup with two major aims. Firstly, to save as many lives as possible without any lifetime morbidity so that they can return to service as active members without any disability. Secondly, to timely evacuate injured to tertiary care units whenever required. Mass casualties can occur anywhere anytime. It is the need of an hour that all the health care professionals and providers must be clinically skilled and have plans to manage such an incident to the best of their capabilities. This is only possible with good triage at the site of incident as well at reception in hospital. The aim is to provide greatest good to greatest number of people and not greatest good to a single patient. Various triage systems are in practice including simple triage and rapid treatment (SMART); jump START pediatric triage

Correspondence: Dr Mobeen Ikram, Department of Anaesthesia, Combined Military Hospital Okara Pakistan

Received: 11 Mar 2019; revision received: 12 May 2020; accepted: 18 May 2020 algorithm; emergency severity index (ESI); sort, assess, life saving interventions, treatment and/or Transport (SALT) being used for triage of casualties. ${ }^{1}$ To decrease mortality in a mass casualty incidents (MCI); reducing pre-hospital time and efficient use of medical facilities is most important. ${ }^{2}$ The pre-hospital time can be improved by increasing the number of ambulances, use of air ambulance and rapid response teams. The hospital efficiency can be improved by creating awareness and knowledge of managing $\mathrm{MCI}$ by prior mass casualty drills; optimizing and organizing hospital resources; backup plan for utilization of auxiliary and affiliated institutes; mobilization of all departments; adequate crowd control measures and manpower training., ${ }^{3,4}$ Unpreparedness can lead to failure at times of need and is usually due to failure of communication, inadequate preparedness, exhaustion of medical resources and fatigue of hospital staff. Positive attitude towards learning and rehearsals can make difference at the time of need. ${ }^{5}$ During the service, the authors had an honor to work at Combined Military Hospital $(\mathrm{CMH})$ as well as various Forward Treatment Centers (FTC) in the South Waziristan region. The hazards of extreme climate; primitive infrastructure; remoteness of the area; road blockade by terrorist and power outr- 
ages as well as ongoing operations posed a challenge unique to medicine only. However, morale support by local commanders and hospital administration was encouraging in overcoming limitations and providing best possible medical care to war wounded casualties of operations. We performed damage control resuscitation and surgeries as well as management of minor trauma at our center. Our purpose was to share our experience of handling mass casualties at this remote location, with an aim to help formulate a policy regarding future training of the doctors.

\section{METHODOLOGY}

After the approval of hospital ethical committee (IERC/Anes/16/01); this case series was conducted at Combined Military Hospital (CMH) Thal and forward treatment centers (FTC) in South Waziristan from Jan 2016 to September 2018.

Inclusion Criteria: A single event of mass casualty with maximum number of wounded from each institute, was included in our study by convenient sampling.

\section{Exclusion Criteria: None.}

The data was collected on a proforma. CMH Thal was a peripheral (class CEE) hospital with eight doctors on the posted strength along with 16 Operating Room Assistants (ORA) and two functioning operation rooms. FTC was a primary healthcare facility in the operational areas with three posted doctors, six ORAs and one functioning opera-ting room. Mass casualty in $\mathrm{CMH}$ was defined as number of cases reporting to hospital, exceeding five cases at a time. Mass casualty at FTC has not been labelled and we took more than two casualties at one time. Triage of incoming injured was done at Medical Reception Center (MRC) with immediate shifting of injured labelled as code red to operating room. An anesthetist and surgeon were involved in resuscitation and perioperative management of the war-wounded patients. Our study outcome was type of injury and surgery performed at the two hospitals. The triage was done in emergency department as per SMART guidelines.

The data was analyzed using Statistical Package for the social sciences (SPSS) version 23. Quantitative variables were presented as frequency and percentage. Chi-square (Fischer's exact test) was used to analyze significance. The $p$-value $\leq 0.05$ was taken as significant. RESULTS

All the 16 patients included in our study were males. We received 11 casualties at $\mathrm{CMH}$ versus five casualties at FTC at one time. The triage classification of both incidences was given as Table-I. The presentation of war wounds to both institute were shown as Figure. Two (18.2\%) patients underwent surgery at CMH versus one $(20 \%)$ at FTC. Damage control surgery (DCS) in one patient $(9.1 \%)$ was done at $\mathrm{CMH}$; whereas damage control resuscitation (DCR) was done in one $(20 \%)$ of the injured at FTC and patients were transferred via air ambulance for definitive surgery and further management. The rest of casualties were transferred to secondary care hospital by road via ambulance. The detail of procedures done at the two institutes is shown in Table-II.

Table-I: Mass casualty triage classes of the two incidences.

\begin{tabular}{l|c|c|c}
\hline & $\begin{array}{c}\text { Combined } \\
\text { Military } \\
\text { Hospital }\end{array}$ & $\begin{array}{c}\text { Forward } \\
\text { Treatment } \\
\text { Center }\end{array}$ & $\begin{array}{c}p \text { - } \\
\text { value }\end{array}$ \\
\cline { 1 - 3 } Red (Immediate) & $2(18.2 \%)$ & $1(20 \%)$ & \\
\cline { 1 - 3 } Yellow (Delayed) & $2(18.2 \%)$ & $1(20 \%)$ & \multirow{2}{*}{0.926} \\
\cline { 1 - 2 } $\begin{array}{l}\text { Green (Minor } \\
\text { wounds) }\end{array}$ & $6(54.5 \%)$ & $2(40 \%)$ & \\
\hline Black (deceased) & $1(9.1 \%)$ & $1(20 \%)$ & \\
\hline
\end{tabular}

Table-II: Comparison of procedures done.

\begin{tabular}{l|c|c|c}
\hline & $\begin{array}{c}\text { Combined } \\
\text { Military } \\
\text { Hospital }\end{array}$ & $\begin{array}{c}\text { Forward } \\
\text { Treatment } \\
\text { Center }\end{array}$ & $\begin{array}{c}p \text { - } \\
\text { value }\end{array}$ \\
\cline { 1 - 3 } $\begin{array}{l}\text { Damage Control } \\
\text { Surgery }\end{array}$ & $1(9.1 \%)$ & - & \\
\cline { 1 - 3 } Chest tube & $1(9.1 \%)$ & - & \multirow{2}{*}{0.346} \\
\cline { 1 - 3 } Hemostasis & $8(71.7 \%)$ & $3(60 \%)$ & \\
\cline { 1 - 3 } $\begin{array}{l}\text { Damage Control } \\
\text { Resuscitation \& transfer }\end{array}$ & - & $1(20 \%)$ & \\
\hline
\end{tabular}

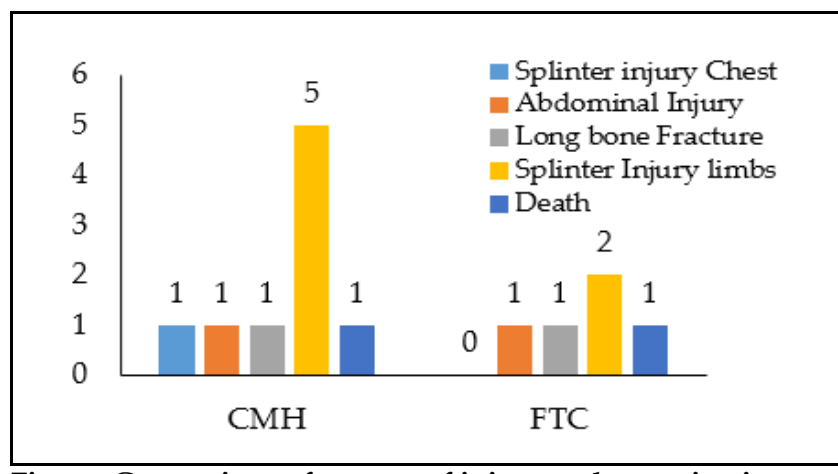

Figure: Comparison of pattern of injury at the two institutes.

\section{DISCUSSION}

Our study showed similar patterns of injury and management done at both hospitals. Although both the MCI may appear to be small in number but the hospitals are medical centers meant for rapid initiation of management and stabilization till transfer to tertiary care centers. According to authors' knowledge, limited data is available for managing mass casualty in third 
world countries. Sarah et al, reported seventy patients who presented to their hospital after a high-energy bombing. Sixty two $(88 \%)$ patients presented without prehospital triage or resuscitation with $4(5.7 \%)$ who were declared dead on arrival. Most were males (78\%) with penetrating shrapnel injury being most common. 36 surgeries were performed at their institute with 4 damage control surgeries. There were no in hospital mortality in the admitted patients. ${ }^{6}$ Similarly, splinter injury limbs were the most common mode of injury at both our treatment centers.

Propper et al, presented multiple casualty incidences in United States Air Force Theater Hospital Iraq. They reported a total of fifty cases; amongst which $24(48 \%)$ required blood transfusion, $25(50 \%)$ required ICU admission, 24 (48\%) required mechanical ventilation with $8 \%$ in-hospital mortality. Penetrating injury to multiple locations was most common (36\%). All their patients were victims of bomb blasts. However, we didn't include the mode of injury in our study and may have included firearm as well as blast injury. ${ }^{7}$

Advance intimation of incoming casualty provided valuable time to organize our setup. We had previously conducted mass casualty exercises on monthly basis and hospital staff was trained accordingly at our hospital. On receiving the news of mass casualty, all the operation theatre staff was instructed to report to the operation theatre. All electro-medical equipment; which were kept up-to-date and in optimal functioning capability; were re-checked and organized. All the anesthetic, analgesic and resuscitation medications were freshly prepared and properly labeled. Additional stretchers and intravenous stands were made available to cater for large number of cases. Theatre staff was assigned predetermined roles as anesthetist or surgical assistants as well as for management of minor injuries including dressing, debridement and stitching. The regimental police (RP) provided security and traffic control while additional manpower like nursing staff were called for nursing care, drawing blood samples of patients and coordination with blood bank. Facilities of laboratory and radiology department were made available and timely availability of investigations despite limited number of staff of both departments helped in quick decision making of the patients. In addition, there was close collaboration with the civil and public sector hospitals like Frontier Constabulary (FC) and Tehsil Head quarter (THQ). These hospitals prepared to accommodate the casualties till their pro-per referral to a tertiary care setup, in case of unexpected influx of patients. The anesthetist performed additional duty of resuscitation and stabilization of the injured as well as provision of adequate analgesia to the patients.

After a review of literature, we were able to learn certain valuable lessons and implement those in our practical experience to improve patients outcome. First of all, as a large number of monitors cannot be made available in any disaster, although not $100 \%$ accurate, radial pulse was monitored which gave a fair idea by its volume.Palpable radial pulse means systolic blood pressure of more than $80 \mathrm{~mm}$ of $\mathrm{Hg} .{ }^{8,9}$ Secondly, Onegative cross matched blood can be transfused in cases of extreme emergency. However, non-availability of platelet concentrate and fresh frozen plasma were our limitations for damage control resuscitation. We used fresh whole blood, whenever damage control resuscitation was necessary. This practice is supported by various other studies.10-12 The donation of blood was voluntary and of one pint only. The desire of soldiers to donate blood to their brother was so appreciable that managing fresh blood or stored blood was not an issue. Thirdly, all patients which were beyond the scope of the hospital or who required specialized and multi-disciplinary approach in a tertiary care hospital were timely evacuated by air or road depending on the condition of the patients and keeping in mind the weather and security conditions as floods, snowfall and heavy rains affect evacuation. The timely and safe transport of critically injured is of utmost importance to avoid preventable deaths. Fourthly, in mass casualty incidents, scale of impact always exceeds the ability of available resources to cope with the casualties and the need for emergency medical team and emergency trauma surgery is maximum during the first 48 hours. ${ }^{13}$ Thus to respond adequately one must be prepared otherwise response will be suboptimal even in large hospitals. ${ }^{14}$ Fifthly, damage control surgery should be performed as early as possible. The primary goal of this surgical intervention is to stabilize the patient, stop bleeding and prevent contamination. ${ }^{15,16}$ We performed damage control surgeries at our hospital under various anesthesia including sedation, nerve blocks, neuro-axial as well as general anesthesia. Lastly, regular mass casualty drill and preparatory exercise as well as individualized standing operating procedure that take into account local resources and limitation should be routinely done. Collander et al, have recommended preparatory courses and rehearsals to be regularly conducted at various levels of emergency medicine as part of war preparedness and disaster management. ${ }^{17}$ Similarly, Alexander has recommended the development of 
living document (standing operation procedures/protocols) based on experience and rehearsals and is periodically updated based on lessons learned. ${ }^{18}$

\section{LIMITATIONS OF STUDY}

Our study had certain limitations. We didn't study the mode of mass casualty and didn't include the demographic profile in detail as all of our injured were young serving personnel.

\section{RECOMMENDATIONS}

We recommend continuous medical education in mass casualty management and speedy evacuation by fully equipped helicopters as being practiced in Pakistan along with continuous sharing of experience to help updating standard operating procedures (SOP) on mass casualty for better patient care with intention to return the injured men to society as useful members with high morale. Transfusion of fresh whole blood is recommended in ongoing massive hemorrhage in the war wounded. We recommend that the blood grouping (ABO as well Rh-antigen) of all the personnel should be done prior to the operation with either a blood group tag or sign incorporated into uniform. The pre-deployment screening serology for hepatitis B and C, HIV, syphilis, human T-cell lymphoma virus; Trypnamosoma scruzi and other common blood born infection should be done for all voluntary donors. In addition, we recommend that personnel may be screened 3-monhtly if deployment is to last more than six months. Training of all the doctors involved in fresh whole blood transfusion should include awareness of risk and adverse effects in donor and recipients. In addition, the healthcare system with education at the grass root level with the optimization of civil and government emergency response teams is advised.

\section{CONCLUSION}

Most of mass casualty at our institute were minor injuries requiring immediate first aid. In addition, the damage control resuscitation and surgery done at these remote locations may have helped prevent mortality and morbidity in the more severely injured.

\section{Conflict of Interest: None.}

\section{Authors' Contribution}

MI: Direct contribution of conception of data, SM: Literature review \& compile results, NZ: Statistical review.

\section{REFERENCES}

1. Culley JM, Syendsen E. A review of the literature on the validity of mass casualty triage systems with a focus on chemical exposures. Am J Disaster Med 2014; 9(2): 137-150.

2. Yu W, Lv Y, Hu C, Liu Xu, Chen H, Xue C. Research of an emergency medical system for mass casualty incidents in Shanghai, China: a system dynamics model. Pat Pref Adher 2018; 12(1): 207-222.
3. Ozoilo KN, Pam IC, Yiltok SJ, Ramyil AV, Nwadiaro HC. Challenges of the management of mass casualty: lessons learned from the Jos crisis of 2001. World J Emer Surg 2013; 38(1): 44-48.

4. Shahzad H, Irfanullah, Shafqat U. Disaster management preparedness: attitudes and previous experience of emergency physi-cians. Br Med J 2018; 1(1): 9-15.

5. Singhal YK, Bhatnagar R, Lal B, Paliwal B. Knowledge, attitudes, and practices of medical internship students regarding disaster preparedness at a tertiary-care hospital of Udaipur, Rajasthan, India. Int J Med Sci Public Health 2016; 5(8): 1613-1616.

6. Sarah AA, Rehman A, Sayyad RH, Haider AH, Bawa A, Zafar SN, et al. Impact of a predefined hospital casualty response plan in limited resource setting with no pre-hospital care system. Injury 2015; 46(1): 156-161.

7. Propper BW, Rasmussen TE, Davidson SB, Vandenberg SL, Clouse WD, Burkhardt GE, et al. Surgical response to multiple casualty incidents following single explosive events. Ann Surg 2009; 250(2): 311-315.

8. Collicott PE, Aprahamian C, Carrico CJ. advanced trauma life support course for physicians. Chicago: American College of Surgeons; 1985 Support. pdf Available at: http://paginas.facmed. unam. $\mathrm{mx} /$ deptos/cirugia_/wp-content/uploads/2018/07/AdvancedTrauma-Life-Support.pdf (Accessed on Nov 12, 2018).

9. Daekin CD and Low JL. Accuracy of advanced trauma life support guidelines foe predicting systolic blood pressure using carotid, femoral and radial pulses: observational study. Br Med J 2000; 321(7262): 673-674

10. Beckett A, Callum J, da Luz LT, Schmid J, Funk C, Glassberg E, et al. Fresh whole blood transfusion capability for special operation forces. Can J Surg 2015; 58(Suppl-3): S153-156.

11. Spinella PC, Strandenes G, Rein EB, Seqhatchain J, Hervig T. Symposium on fresh whole blood for severe hemorrhagic shock: from in-hospital to far forward resuscitation. Transfuse Apher Sci 2012; 46(1): 113-117.

12. Strandese G, Cap AP, Cacic D, Lunde TH, Eliassen HS, Hervig T, et al. Blood Far Forward-a whole blood research and training program for austrene environment. Transfusion 2013; 53(Suppl-1): 124S-130S.

13. Geiling J, Burkle FM, West TE, Uyeki TM, Amundson D, Dominguez-Cherit G, et al. Resource-poor settings: response, recovery, and research: care of the critically ill and injured during pandemics and disasters: CHEST consensus statement. Chest 2014; 146(Suppl-4): e168S-77S.

14. Langhelle A, Lossius HM, Stifvast T, Bjornsson HM, Lippert FK, Ersson A, et al. International EMS systems: The Nordic countries. Resuscitat 2004; 61(1): 9-21.

15. Weber DG, Bendinelli C, Balogh ZJ. Damage control surgery for abdominal emergencies. Br J Surg 2014; 101(1): e109-118.

16. Roberts DJ, Bobrovitz N, Zygun DA, Ball CG, Kirkpatrick AW, Faris $\mathrm{PD}$, et al. Indications for use of damage control surgery in civilian trauma patients: a content analysis and expert appropria-teness rating study. Ann Surg 2016; 263(1): 1018.

17. Collander B, Green B, Millo Y, Shamloo C, Donnelan J, De-Atley C. Development of an "All-Hazard" hospital disaster preparedness training course utilizing multi-modality teaching. Prehosp Disast Med 2008; 23(1): 63-67.

18. Alexander D. Disaster and emergency planning for preparedness, response, and recovery; 2015. [Internet] Availabe at: https://www. semanticscholar.org/paper/Disaster-and-Emergency-Planning-forPreparedness\%2C-Alexander/31c0b1eb3b76eef11964338d7c70934c6cd2db3d (Accessed on November 12,2018). 